\title{
Are grazer-induced adaptations of bacterial abundance and morphology time- dependent?
}

\author{
Gianluca CORNO \\ CNR, Institute of Ecosystems Study, Largo V. Tonolli 50, 28922 Verbania-Pallanza, Italy \\ e-mail corresponding author: g.corno@ise.cnr.it
}

\begin{abstract}
Predation by protists is a well known force that shapes bacterial communities and can lead to filamentous forms and aggregations of large cell clusters. These classic resistance strategies were observed as a direct consequence of predation by heteroand mixotrophic flagellates (the main group of bacteria predators in water) on natural assemblages of bacteria and on single plastic strains. Recently it was shown that a long time exposure (about 30 days) of a bacterial strain, characterized by high degree of phenotypic plasticity, to flagellates, without direct predation, enhanced the formation of resistant forms (filaments) in a continuous culture system. Target prey populations and predators were separated by a dialysis membrane. Moreover, the positive impact on bacterial growth, due to the chemical excretes released by flagellates was demonstrated for exudates of photosynthetic activity. The same positive impact may also be seen in response to exudates related to grazing. In this study, two short-term experiments $(<100$ hours) were conducted to test for modifications in the morphology and productivity of three different bacterial strains that were induced by the presence of active predators, but without direct predation. The growth and morphological distribution of each of the selected strains was tested separately using batch cultures. Cultures were either enriched with carbon in the presence or absence of flagellate predators, or included pre-filtered exudates from flagellate activity. In a second experiment, bottles were provided with a central dialysis bag that contained active flagellates, and were inoculated with the selected bacterial strains. In this way, bacteria were exposed to the presence of predators without direct predation. The bacterial strains used in this experience were characterised by a high degree of phenotypic plasticity and exhibited different successful strategies of resistance against grazing. The flagellates selected as predators belong to two voracious species: Spumella sp. and Ochromonas sp., strictly heterotrophic and mixotrophic, respectively. For all the treatments, it was impossible to find any clear evidence of a morphological adaptation stimulated by the mere presence of flagellates. On the other hand, for all bacterial strains the enrichment of the media due to the release of exudates, resulted in higher growth rates and higher abundances, confirming that grazers are fundamental actors involved in the inner recycling of the microbial loop.
\end{abstract}

Key words: flagellate grazing, phenotypic plasticity, filamentous bacteria, aggregates

\section{INTRODUCTION}

The impact of grazing by hetero- and mixotrophic nanoflagellates on aquatic bacterial assemblages often results in a shift in the size and shape of bacterial cells, and enhances the development of forms that are inedible for the predators. It has been demonstrated that different bacterial strains are not equally vulnerable to grazers, and only some of them can develop different mechanisms of resistance against predation by bacterivores (e.g., morphological adaptations, toxicity, motility, cell communication, and exopolymers production; reviewed by Jürgens \& Matz (2002), Pernthaler (2005), Matz \& Kjelleberg (2005). Many bacterial taxa can, under appropriate growth conditions, exceed the size limit that can be handled and engulfed by flagellates. In this way, bacteria can acquire a complete, morphologically determined, grazing resistance against this type of predators (Pernthaler et al. 1997).

How this shift is stimulated by the presence of grazers is still debated. In general, for the classical phytoplankton-zooplankton food chain, the impact of predation must be considered as mediated by the feeding selectivity of grazers (DeMott 1995) and phenotypic adaptations of prey organisms, that is determined by chemical signals and inducible defences (van Donk 1998). These chemical signals are released by predators during grazing activity. In particular, large amounts of several dissolved organic substances are released during the digestion of prey.

Is this assumption valid for bacteria-flagellates systems as well? Pernthaler and co-workers (1997) first speculated about the role of infochemicals, released by predators during the activity of grazing, in the stimulation of a shift in bacterial forms from edible to inedible cells. In a recent article on bacterial adaptations against flagellate predation (Corno \& Jürgens 2006), the direct association between the formation of inedible bacterial forms (filaments) and the presence of flagellates was clearly demonstrated for the plastic strain Flectobacillus sp. GC5. Moreover, the authors showed for the first time that the shift from a bacterial population dominated by edible forms to a population dominated by inedible ones was directly mediated by the simple presence of predators, without any direct predation. However, this response only occurred after a period of 7-10 days of 
continuous exposure in the same environment. The system used for those experiments was a series of continuous cultures provided with a central dialysis bag. This allowed bacteria to experience the chemical presence of predators, but kept flagellate predators enclosed in a central cage. The exudates released by flagellates act as an additional nutrient source for bacteria. The total production of a bacterial population is mainly determined by the availability of nutrients. Nutrients are largely represented by autochthonous sources of the systems in nature or by the amount of nutrients provided with the substrate in the laboratory. In some lakes, allochthonous humic substances may be equally important (Bano et al. 1997). Furthermore, organic exudates (mainly carbon) released by eukaryotic phytoplankton (Baines \& Pace 1991), by cyanobacteria (van Hannen et al. 1999), or by their grazers (Brussaard et al. 1995) are known to be as an important organic substrates for bacteria in many aquatic ecosystems. A slight increment in bacterial abundances in the first hours of exposure to grazing by heterotrophic nanoflagellates was found in several laboratory experiments (Matz et al. 2002; Hahn \& Höfle 1999) and a positive correlation between bacterial biomass and presence of grazers (without direct predation) was found by Corno \& Jürgens (2006), in long-term continuous cultures.

In the present study, these two important aspects of bacteria-flagellates interactions were analyzed by performing two short-term experiments in laboratory systems for a period of about 100 hours (4 days). Firstly, I assessed the impact of the predators presence (without direct predation) on the bacterial morphology, in order to test the speculations of Hahn \& Höfle (1999) and Corno \& Jürgens (2006) in chemostat experiments, and of Pernthaler and co-workers (2004) in freshwater plankton, that only a sufficiently long exposure to a grazer-mediated environment can result in the shift towards the development of filaments, aggregates or other resistant morphologies. Secondly, I assessed the impact of the predator presence, and the relative effect of the exudates released by them, on the growth dynamics of the single bacterial strains selected.

\section{MATERIALS AND METHODS}

In order to select plastic strains to test for effect of predators presence, several bacterial strains were isolated from Lake Schösee (North Germany) and grown under high grazing pressure by heterotrophic nanoflagellates (HNF) in continuous culture systems, in a dark and cold $\left(13^{\circ} \mathrm{C}\right)$ room (simulating the lake environment) for a month. Chemostat vessels $(500 \mathrm{ml})$ were filled with WC medium (Guillard \& Lorentzen 1972) and enriched with $10 \mathrm{mg}$ Glucose (Glc) $\mathrm{l}^{-1}$. Dilution rate was also fixed at $0.1 \mathrm{day}^{-1}$. Three grazing resistant strains were plated on agar and used in this study: GCWC2, GC-WC3 and GC-WC5 (Flectobacillus sp. strain GC5, Corno \& Jürgens 2006). Under grazing pressure, strain GC-WC3 can produce large clusters of 20-200 cells, GC-WC5 develops long filaments and chains of cells (up to $40 \mu \mathrm{m}$ ), and strain GC-WC2 can form both filamentous and aggregate forms (Matz et al. 2002; Corno \& Jürgens 2006). Clonal cultures of all the strains were obtained from single colonies.

Axenic cultures of Ochromonas sp. isolated again from Lake Schöhsee were maintained on suspensions of heat-killed Pseudomonas putida MM1, a bacterial strain already described as ideal food source for nanoflagellates (Corno \& Jürgens 2006).

Two flagellates were selected to be separately tested for their influence on bacterial dynamics and thus were inoculated on different plates: a pure culture of the strictly heterotrophic Spumella sp. kindly provided by C. Matz and an axenic culture of the mixotrophic flagellate Ochromonas sp., isolated by Corno \& Jürgens. Spumella sp. exudates are strictly related to the activity of grazing, while Ochromonas sp. exudates can be derived by photosynthesis or by grazing, depending on the conditions (light, amount of available prey) of the culture. Cultures were obtained from the microbial library of the Max Planck Institute for Limnology (Plön, Germany). From these cultures, the following systems, designed for this study, were inoculated.

\subsection{Batch populations exposed to HNF exudates}

The mixotrophic flagellate Ochromonas sp. was inoculated in $75 \mathrm{ml}$ batch cultures containing bacterial populations belonging to the three strains selected for this study (Corno \& Jürgens 2006). After 5 days of exposure to predation under mainly dark conditions (4 hours of daylight per day) the content of each batch was filtered on $0.2 \mu \mathrm{m}$ Nuclepore filters, and the flowthrough, enriched with Ochromonas sp. exudates, was used as a media for three new batch cultures $(75 \mathrm{ml})$, in which each of the three selected bacterial strains were inoculated (Fig. 1A) (inoculum: $100 \mu 1$, about $5 \times 10^{5}$ cells).

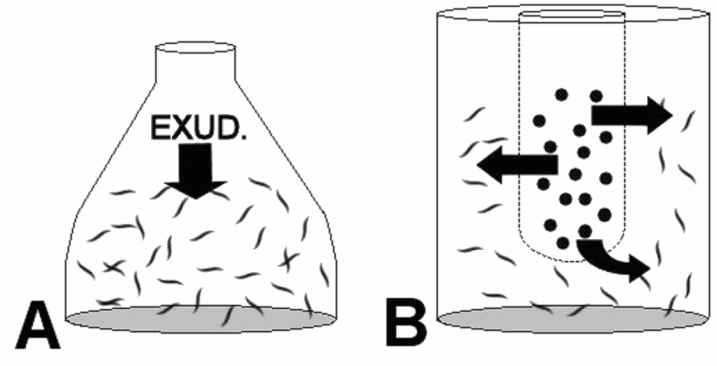

Fig. 1. Experimental settings: in $\mathbf{A}$ batch with bacteria (shaped rods) inoculated in liquid substrate obtained by exudates released by flagellates during grazing activity. In $\mathbf{B}$, bottle provided by a central dialysis bag (with flagellate, black spots, inoculated inside) and the tested bacterial population outside. 
A comparative treatment was settled by performing identical batches enriched with WC medium instead of grazing exudates and provided with extra glucose for a final concentration of $5 \mathrm{mg} \mathrm{Glc} \mathrm{l}^{-1}$. This treatment was performed both without and with predators (inoculum of $5 \times 10^{4}$ Ochromonas sp. cells), in order to compare bacterial dynamics with exudates but without predation, to bacterial dynamics with direct predation, and an additional small amount of substrate that did not result from microbial activities. About $5 \times 10^{5}$ bacterial cells were inoculated in each batch. Three replicates for each treatment and for each bacterial strain were settled (27 batches in total). The experiments ran for 96 hours after the addition of the bacterial inoculum.

\subsection{Dialysis-bag bottles}

Batch experiments were performed in $250 \mathrm{ml}$ bottles that were filled with WC medium supplemented with different glucose concentrations (5 and $\left.20 \mathrm{mg} \mathrm{l}^{-1}\right)$. A dialysis bag (regenerated cellulose, 15,000 MWCO, ZelluTrans/Roth, Karlsruhe) with a volume of $100 \mathrm{ml}$ was inserted in each bottle, thereby reducing the external volume to approximately $150 \mathrm{ml}$ (Fig. 1B). From clonal pre-cultures, the three selected bacterial strains (100 $\mu$ l, about $5 \times 10^{5}$ cells) were inoculated into different bottles outside of the dialysis bags (final concentration approximately $3 \times 10^{3}$ cells $\mathrm{ml}^{-1}$ ). The bags were inoculated with either Spumella sp. (final concentration $c a$ 120 cells $\left.\mathrm{ml}^{-1}\right)$ or $P$. putida MM1 $\left(2.3 \times 10^{6}\right.$ cells $\left.\mathrm{ml}^{-1}\right)$ as a predator. Three replicates were performed for each of the treatments, and for each of the three selected bacterial strains, for a total of 18 batches that ran for 96 hours.

\subsection{Cell numbers and morphology}

Bacterial and flagellate cell numbers were determined daily from formalin ( $2 \%$ final concentration). Fixed samples were stained with 4',6-diamidino-2phenylindole (DAPI) (Porter \& Feig 1980), filtered onto $0.2 \mu \mathrm{m}$ pore-size polycarbonate filters and counted by epifluorescence microscopy. At least 1000 bacteria were counted per sample. Bacterial cell size measurements were done from DAPI stained samples. For some samples with mainly small morphotypes an automated image analysis system (SIS GmbH, Münster, Germany) was used which measures the area and the perimeter of 300-500 cells, which are then used to calculate cell dimensions (volume, length, width) according to the algorithms given in Massana et al. (1997). Morphological changes (e.g. cell elongation) were mainly reflected by a change in cell length, whereas cell width stayed relatively constant. For most samples only cell length was assessed (Corno \& Jürgens 2006). For this, the length of at least 100 randomly selected cells per filter was directly measured with the help of an ocular grid. Cells longer than $7 \mu \mathrm{m}$, and thus inedible for Ochromonas sp. and Spumella sp. (Corno \& Jürgens 2006; Jürgens \&
Matz 2002), were considered separately and included both filaments and aggregates composed of more than 10 cells.

\subsection{Statistical analyses}

Bacterial dynamics and the relative proportion of different morphotypes in all treatments were tested for significance using a 2-way repeated-measures ANOVA, with Bonferroni corrected $t$-tests and post-hoc comparisons. Statistical analyses were performed with SigmaStat 3.0 packed with SigmaPlot 9.0 (Systat Software, Inc.).

\section{RESULTS}

\subsection{Bacterial dynamics with exudates}

The experiment testing for the impact of exudates on bacterial populations generally resulted in higher abundances (Fig. 2). Strain GC-WC5 reached at time 96 hours the value of $3.1 \pm 0.3 \times 10^{6}$ cell ml $^{-1}$ when grown in

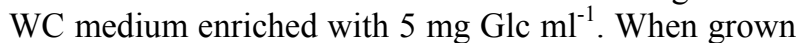
in exudates they reached $3.9 \pm 0.3 \times 10^{6}$ cell ml ${ }^{-1}$, and developed a population significantly larger $(p=0.019)$ than the control in glucose. When exposed to direct predation by Ochromonas sp., bacterial abundance reduced to $0.4 \pm 0.1 \times 10^{6}$ cell $\mathrm{ml}^{-1}$.

Similar trends and relative abundances were measured for strain GC-WC2: a number of $4.4 \pm 0.7 \times 10^{6}$ cell $\mathrm{ml}^{-1}$ was measured as the mean of control treatments in glucose. A concentration of $5.1 \pm 0.9 \times 10^{6}$ cells ml ${ }^{-1}$ was detected in exudates treatments. The trends between time 24 and 96 for the two treatments resulted were significantly different $(p=0.034)$. Under grazing pressure, the abundance was reduced to $0.3 \pm 0.1 \times 10^{6}$ cell ml$^{-1}$.

Despite higher abundances at time 96 hours in the exudates treatment compared to control treatment $(2.6 \pm$ $0.7 \times 10^{6}$ cell ml ${ }^{-1}$ and $3.5 \pm 0.8 \times 10^{6}$ cell $\mathrm{ml}^{-1}$, respectively), it was impossible, for strain GC-WC3, to identify significant differences in the temporal development of the two bacterial populations. Under Ochromonas sp. grazing, bacterial abundance resulted in a concentration of $0.4 \pm 0.1 \times 10^{6}$ cell $\mathrm{ml}^{-1}$.

\subsection{Bacterial dynamics in dialysis bottles}

Using bottles provided with a central dialysis bag, it was possible to test bacterial growth in treatments were prey and predators were sharing the same medium, but without direct predation (Fig. 2). The relative impact of the presence of predators (Spumella sp.) was tested in treatments with low and with high substrate supply.

After 96 hours of exposure in the batches, bacterial strain GC-WC5 developed populations lower than $5 \times 10^{6}$ cell ml${ }^{-1}$ in the nutrient poor treatment, and between 20 and $25 \times 10^{6}$ cell ml ${ }^{-1}$ in the richer ones, for both treatments with Spumella sp. in the bag and treatments without predators. The mean abundance of treat- 


\section{Exudate exp.}

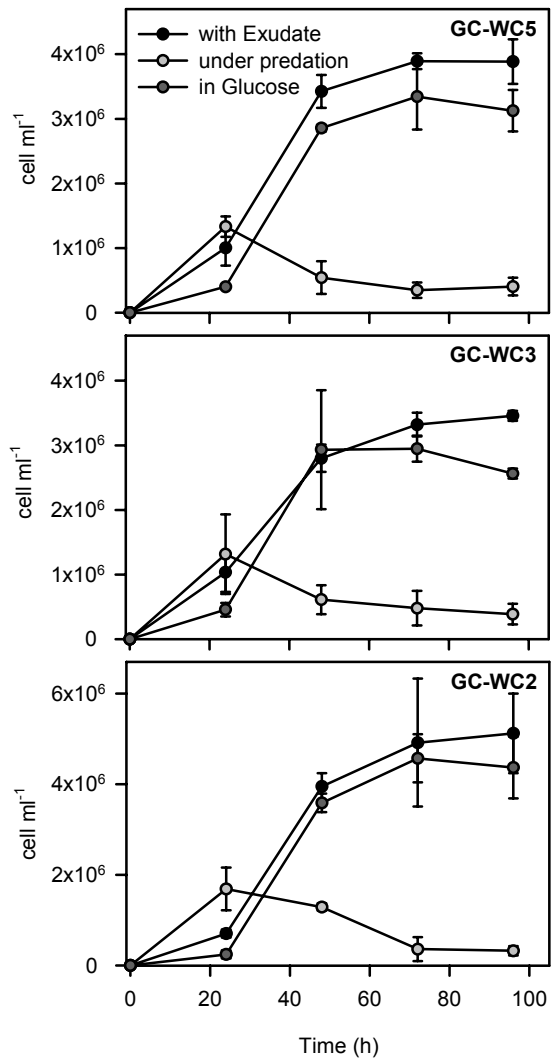

Dia-bag exp.

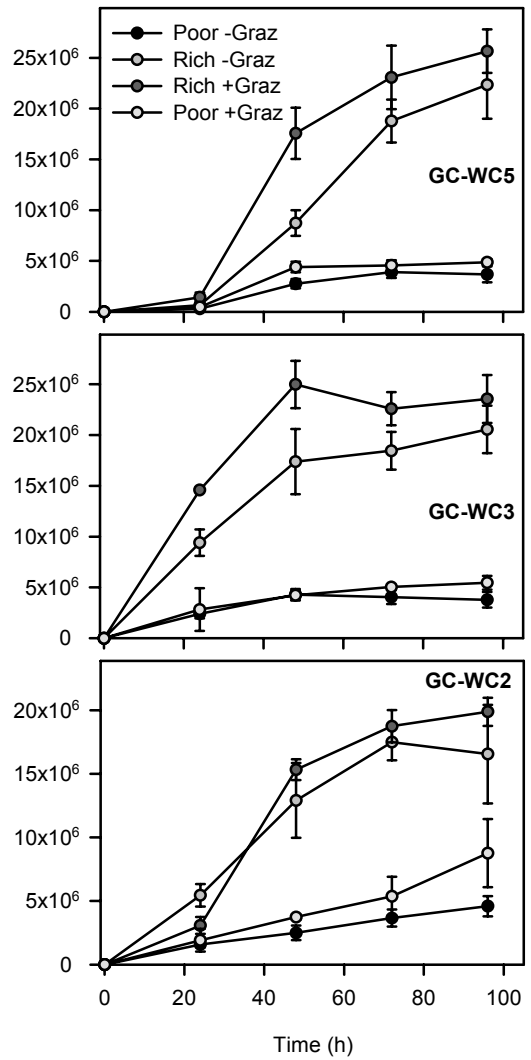

Fig. 2. Bacterial population dynamics in exudate-batches (left column) and in dialysis bag-bottles (right column). Data expressed as mean of three replicates \pm standard deviation. Relative bacterial strain name is written directly in the plots.

ments exposed to the presence of the grazers was higher for all samples after 24 hours, but a significant increase through the time series was found only for the treatments rich in nutrients $(\mathrm{p}=0.041)$.

Very similar results were obtained for the strain GCWC3. Low nutrient bottles resulted in abundances below $5 \times 10^{6}$ cell ml ${ }^{-1}$ for both treatments, with mean values that were slightly higher for bacterial populations exposed to Spumella sp. However, there was no significant difference between replicate series. The average bacterial populations of $20.6 \pm 2.6 \times 10^{6}$ cell $\mathrm{ml}^{-1}$ for control treatments without predators, and of $23.6 \pm$ $2.4 \times 10^{6}$ cell ml${ }^{-1}$ with grazers in the bags were measured after 96 hours in bottles with high amount of glucose provided. In this case, the difference between the two treatments was significant $(p=0.033)$ through the period 24-96 hours.

Strain GC-WC2 showed more contradicting trends. If the assumption of slightly higher mean abundances for treatments with predators in the bag was confirmed for treatments enriched with low glucose amounts $(4.6 \pm$ $0.8 \times 10^{6}$ cell ml $\mathrm{m}^{-1}$ against $8.8 \pm 2.7 \times 10^{6}$ cell ml $\mathrm{m}^{-1}$ ), it could not be confirmed by highly productive treatments where the values were always within the relative standard deviation intervals. For one time point $(24 \mathrm{~h})$ the value of the grazer free sample was more abundant. Trends relative to the same substrate supply did not show statistically significant differences.

\subsection{Morphological distribution}

Three main bacterial morphologies were settled and described, and the whole bacterial populations were defined following the given definitions. The first two morphologies were directly derived from the shape of the cell: rods or cocci represented all free living cells, that were shorter than $7 \mu \mathrm{m}$ and edible for nanoflagellates; filaments included single cells or chains with a length longer than $7 \mu \mathrm{m}$ and thus inedible. A third group was represented by aggregates of cells, also inedible for nanoflagellates, and composed of more than 10 bacteria stacked together, independently of their shape or size of the single cells.

The examination of the results from the experiment in batches enriched with exudates allows a preliminary comparison of the development of different morphologies according to the presence or the absence of predators.

In the absence of predators (Fig 3), all the three strains developed mainly free living edible forms (at 96 hours neither for strain GC-WC5 nor for GC-WC2 


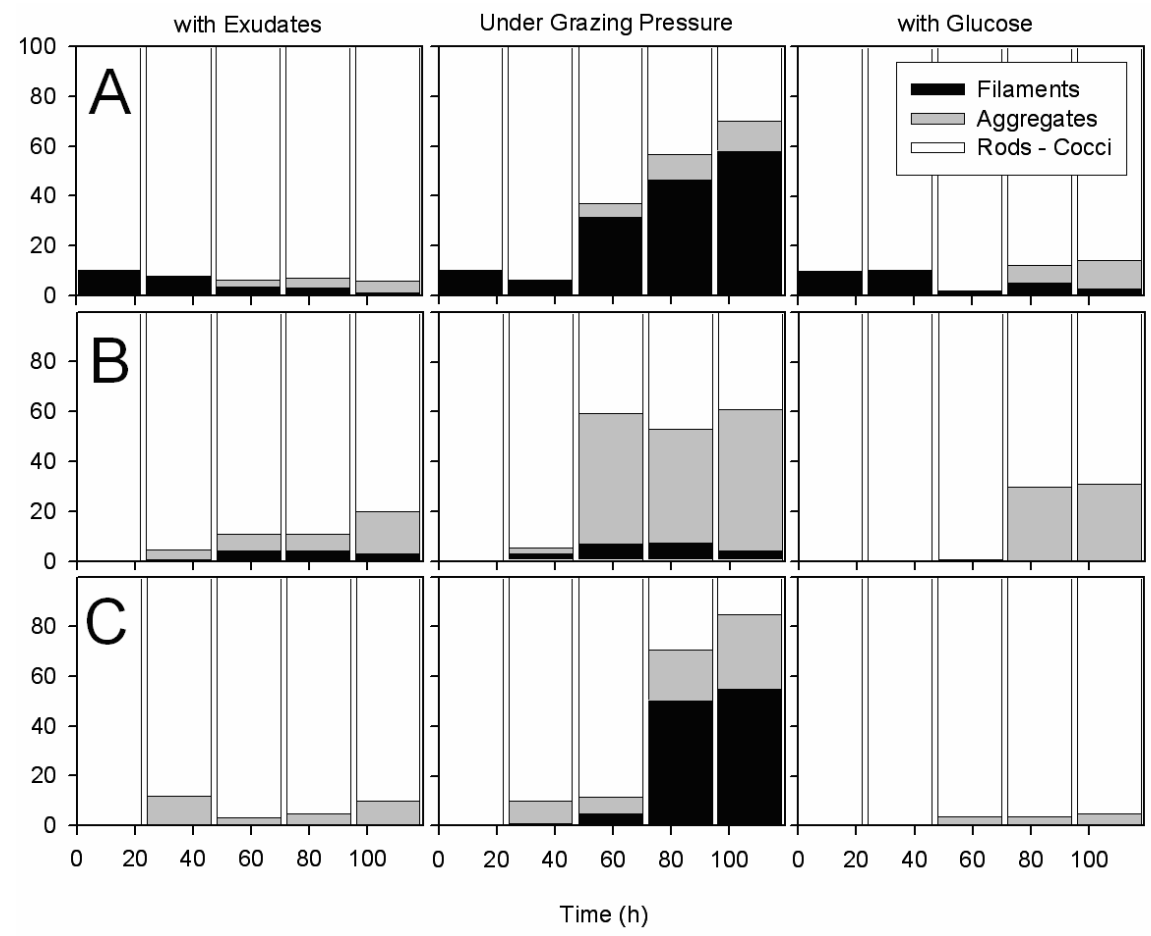

Fig. 3. Relative proportion of the three bacterial morphologies observed in exudate experiment, under a direct grazing pressure, and with additional glucose (control). Line A refers to strain GC-WC5, line $\mathbf{B}$ to GC-WC3, and line $\mathbf{C}$ to strain GC-WC2. Values expressed as mean of three replicates treatments.

inedible forms reached $10 \%$ of total bacterial number, while strain GC-WC3 developed about $30 \%$ of aggregates). In the presence of predators the situation changed: strain GC-WC5 was composed by almost $80 \%$ of inedible forms ( $59 \%$ of filaments), GC-WC3 reached about $60 \%$ (almost only aggregates), and GC-WC2 reached more than $80 \%$ ( $55 \%$ were filamentous forms).

When the input of nutrients was provided by the exudates of the nanoflagellate grazing activity, the development of resistant morphotypes was not detected for the selected strains. Percentages of inedible forms was, at the end of the experiment, lower than $10 \%$ for strains GC-WC5 and GC-WC2, and about 20\% (of aggregates) for strain GC-WC3.

Very similar distribution occurred also in the bottles provided with dialysis bags: the proportion of inedible forms never exceeded $30 \%$ of total bacterial abundance for the strain GC-WC5, and was always lower than $20 \%$ for the other two strains. A slight tendency for an increase in resistant morphologies appeared in the presence of grazers for strains GC-WC2 and GC-WC3, raising from $0 \%$ at time $24 \mathrm{~h}$ to about $10 \%$ of total bacterial populations after 96 hours even if the relative proportion of different morphotypes was never significantly different when treatments were compared.

\section{DISCUSSION}

The positive correlation between bacterial abundance and the exposure to flagellate exudates was generally found in batches (in both, exudate-exposed and dialysis bag-provided batches), and was more significant in more productive systems.

Clear outcomes characterized the batches tested for the enrichment with exudates. A significant positive impact of exudates on bacterial abundances, compared to a low $\left(5 \mathrm{mg} \mathrm{ml}^{-1}\right)$ amount of glucose provided in the controls, was measured for strains GC-WC5 and GCWC2. Also for the strain GC-WC3, even if not statistically demonstrable, it was possible to identify a tendency toward increasing abundances when exposed to HNF exudates.

Exposing the strains to the presence of predators, using bottles with a central dialysis bag, did not change the situation, and the indirect positive impact of grazer presence was measured, for both systems designed to be close to starving conditions and for systems supplied with high amounts of glucose.

These trends were not surprising and could be explained by speculating on the nature of the additional source of organic carbon represented by Ochromonas sp. and Spumella sp. exudates, which were mainly composed of organic carbon and other dissolved nutrients immediately available for bacteria (Pernthaler et al. 1997).

The two grazers selected are characterized by different survival strategies: strictly hererotrophic Spumella sp., and mixotrophic Ochromonas sp. For this reason, it was reasonable to test the relative impact of the respective exudates that, for Ochromonas sp., were composed of the excretions due to grazing activity but also due to photosynthesis (which was limited in the experiment by 
periodically obscuring the cultures). Despite this composed nature, the impact of the exudates was similar, and the reaction caused in the bacterial populations was comparable. It is then possible to argue that the nutritional power of the exudates of Ochromonas sp. is independent of the activity performed, and that the total amount of nutrients released is similar without regards to the activity (hetero- or autotrophic).

When under direct grazing pressure bacteria developed resistant morphotypes, which became the main part of the bacterial population within 48-60 hours. On the other hand, the analysis of the morphological composition of the bacterial populations confirmed, for both experiments, that a period of at least 6-7 days of continuous exposition to grazing exudates (Corno \& Jürgens 2006), but without predation, is necessary in order to allow for the development of a significantly more resistant morphotypes. This conclusion was independent of the morphological adaptation that characterized the bacterial strain. Neither GC-WC5 (filamentforming strain), nor GC-WC3 (aggregable strain), nor GC-WC2 (able to develop both resistant forms) changed their morphological composition at the end of each of the short-term experiments (time 96 hours), but always changed when exposed to direct predation after 72 hours (Fig. 3).

Obviously, predation by flagellates is an important force controlling the dynamics of planktonic bacteria. It is possible to estimate, in a proper way, not only the direct (negative) impact of grazing, but also the positive effect of the recirculation of nutrients related to the predatory activity. By doing so, this would help improve our understanding of the inner fluxes regulating the microbial food web. On the other hand the demonstration of the impossibility for bacterial strains to develop inedible forms simply by exposing them to the presence of grazers for a few hours suggests the importance of natural selection imposed by predation in natural systems. Bacteria can respond to the presence of predators, probably by being alerted by chemical triggers released by the predators themselves, but only the simultaneous effect of triggers and predation, allow the costly and less competitive (Corno \& Jürgens 2006) resistant morphologies to successfully compete with edible bacterial cells.

\section{ACKNOWLEDGMENTS}

This work was supported by grants Ju 367/2-2 and Ju 367/2-3 from the German Science Foundation (DFG). Many thanks to C. Schleker and I. Schulz for technical assistance and to K. Jürgens, C. Matz, B. Modenutti, U. Dorigo and C. Callieri for critical comments.

Received: January 2006

Accepted: April 2006

\section{REFERENCES}

Baines, S.B. \& M.L. Pace. 1991. The production of dissolved organic matter by phytoplankton and its importance to bacteria-patterns across marine and fresh-water systems. Limnol. Oceanogr., 36: 1078-1090.

Bano, N., M.A. Moran \& R.E. Hodson. 1997. Bacterial utilization of dissolved humic substances from a freshwater swamp. Aquat. Microb. Ecol., 12: 233-238.

Brussaard, C.P.D., R. Riegman, A.A.M. Noordeloos, G.C. Cadee, H. Witte, A.J. Kop, G. Nieuwland, F.C. Vanduyl \& R. Bak. 1995. Effects of grazing, sedimentation and phytoplankton cell lysis on the structure of a coastal pelagic food web. Mar. Ecol. Prog. Ser. 123: 259-271.

Corno, G. \& K. Jürgens. 2006. Direct and indirect effects of protist predation on population size structure of a bacterial strain with high phenotypic plasticity. Appl. Environ. Microbiol., 72(1): 78-86.

DeMott, W.R. 1995. Effect of prey hardness on size-selective feeding by Daphnia. Hydrobiologia, 307: 127-138.

Hahn, M.W. \& M.G. Höfle. 1999. Flagellate Predation on a Bacterial Model Community: Interplay of Size-Selective Grazing, Specific Bacterial Cell Size, and Bacterial Community Composition. Appl. Environ. Microbiol., 65: 48634872

Guillard, R. \& C. Lorenzen. 1972. Yellow-green algae with chlorophyllide c. J. Phycol., 8: 10-14.

Jürgens, K., \& C. Matz. 2002. Predation as a shaping force for the phenotypic and genotypic composition of planktonic bacteria. Antonie van Leeuwenhoek, 81: 413-434.

Massana, R., J.M. Gasol, P.K. Björnsen, N. Blackburn, A. Hagström, S. Hietanen, B.H. Hygum, J. Kuparinen \& C. Pedrós-Alió. 1997. Measurement of bacterial size via image analysis of epifluorescence preparations - description of an inexpensive system and solutions to some of the most common problems. Sci. Mar. (Barc.), 61: 397-407.

Matz, C., P. Deines \& K. Jürgens. 2002. Phenotypic variation in Pseudomonas sp. CM10 determines microcolony formation and survival under protozoan grazing. FEMS Microbiol. Ecol., 39: 57-65.

Matz, C. \& S. Kjelleberg. 2005. Off the hook - how bacteria survive protozoan grazing. Trends Microbiol., 13: 302307.

Pernthaler, J., T. Posch, K. Šimek, J. Vrba, R. Amann \& R. Psenner. 1997. Contrasting bacterial strategies to coexist with a flagellate predator in an experimental microbial assemblage. Appl. Environ. Microbiol., 63: 596-601.

Pernthaler, J., E. Zöllner, F. Warnecke, \& K. Jürgens. 2004. Bloom of filamentous bacteria in a mesotrophic lake: identity and potential controlling mechanism. Appl. Environ. Microbiol., 70: 6272-6281.

Pernthaler, J. 2005. Predation on Prokariotes in the water column and its ecological implications. Nat. Rev. Microbiol., 3(7): 537-546.

Porter, K. G. \& Y. F. Feig. 1980. The use of DAPI for identifying and counting aquatic microflora. Limnol. Oceanogr., 25: 943-947.

van Donk, E. 1998. Switches between clear and turbid water states in a biomanipulated lake (1986-1996): The role of herbivory on macrophytes. In: Jeppesen, E., Ma. Søndergaard, Mo. Søndergaard, \& K. Christoffersen (Eds), The structuring role of submerged macrophytes in lakes. Springer: 290-297.

van Hannen, E.J., G. Zwart, H.J. Gons \& M.P. van Agterveld. 1999. Changes in bacterial and eukaryotic community structure after mass lysis of filamentous cyanobacteria associated with viruses. Appl. Environ. Microbiol., 65: 795801. 